\title{
Un caos perfecto: El cine de Emir Kusturica
}

Evelyn ERLIJ*

Desentrañar la vida de este cineasta, capaz de convertir el caos en perfección, es una tortura exquisita sólo para quien tenga en el cuerpo una sobredosis de él suficiente como para soportarla. Aunque su nombre ya está inserto en la historia del séptimo arte como el director que más premios ha ganado en el Festival de Cannes, el hombre tras la cámara es aún un enigma difícil de descifrar, no solo por la complejidad y el barroquismo de sus creaciones, sino también por la excesiva contradicción de sus dichos y sus posturas.

\section{"Cuando Yugoslavia desapareció, me volví invisible"1}

-Emir Kusturica.

Mientras un niño incrusta sus grandes ojos en la mirada perdida de un pavo, un gato a su lado lo emula y logra que una paloma lo contemple sin parpadear. Sin oponer resistencia, se entrega a la profundidad de sus cristales amarillos y sucumbe de un golpe contra la hierba escarchada. En el preciso momento en que el felino se arroja en un salto vivaz sobre su hipnotizada víctima, otro niño más pequeño lo detiene violentamente al pisarle sin querer la cola. Inexpresivo, avanza hacia las líneas del tren, a pesar de escucharse el vaporoso silbato de un carro que se aproxima de frente. En el cielo vuela una novia que roza con su velo las rojizas hojas de un árbol, agarrotado por una banda de gitanos atados a su tronco. La delirante melodía que emiten sirve de cortejo al mortal que estrangula frustradamente su cuello con la campana de una iglesia, mientras el pequeño sonámbulo continúa su camino con ojos cerrados y pasos firmes contra el tren. La novia desaparece, el muerto se despierta, el pavo se echa a volar y la máquina se detiene ante un burro suicida que llora de amor sobre los rieles.

Sin inmutarse, un hombre contempla la escena aspirando el humo de un puro clavado entre los dientes. Su par de ojeras y su pelo desgreñado lo hacen lucir tan cansado como si hubiese sido el creador de todo aquello. Existen tantas historias sobre él, que resulta casi imposible saber quién realmente es. Se dice que inventa realidades mágicas con el lente de una cámara, que narra historias como músico y que compone melodías como cineasta. Algunos creen que es serbio ortodoxo, otros que es bosnio musulmán y unos pocos despistados aseguran que es gitano. Lo tildan de feroz déspota y de tierno bárbaro. De indomable y de sometido. Palabras extremas y discordantes hacia quien precisamente se aferra de las contradicciones del ser humano para narrar historias trágicas, pero eufóricas; brutales y al mismo tiempo humanas.

La expresión mustia de su rostro parece reflejar un constante desencanto con el mundo, pero su imponente voz despliega una vitalidad y una fuerza capaz de aplastar a cualquiera que ose oponérsele. Como sus cintas más grandes -Papá Salió en Viaje de Negocios $^{2}$, Tiempo de Gitanos ${ }^{3}$, Underground ${ }^{4}$ y Gato Negro Gato Blanco ${ }^{5}-$ es

\footnotetext{
* Estudiante de la Escuela de Periodismo. Instituto de la Comunicación e Imagen. Universidad de Chile.

${ }^{1}$ GRUNBERG, Serge. Il était une fois Underground. Editorial Cahiers du Cinéma. Francia. 1995

${ }^{2}$ Papá Salió en Viaje de Negocios (Otac na Službenom Putu). Forum Sarajevo. Yugoslavia. 1985.

${ }^{3}$ Tiempo de Gitanos (Dom za Vešanje). Forum Sarajevo. Yugoslavia/Italia/Gran Bretaña. 1989.
} 
desenfrenado e impredecible. Y tal como sus personajes, irradia una poderosa mezcla de bravura y vulnerabilidad ${ }^{6}$.

Cada cierto tiempo se le ve vagando por estos paisajes oníricos, pero se sabe que es un hombre de ninguna parte. De donde alguna vez vino, no queda más que la nostalgia de un sueño multiétnico que despertó entre estruendos de bombas y ríos de sangre que bañaron las manos de quienes, buscando libertad, creyeron que la única forma de obtenerla era alzando las armas contra sus hermanos de tierra.

Con su apabullante tono grave, lanza un par de frases en una lengua eslava olvidada, cuyas palabras atesoran un pasado destruido por la artillería nacionalista. La guerra desintegró su país, extinguió su idioma y convirtió el lugar que lo vio nacer en la capital de una entidad política con la cual no se reconoce. El serbo-croata se diluyó en serbio, bosnio y croata; Sarajevo es ahora parte de una nación conocida como Bosnia y Yugoslavia dejó de existir.

Despojado de todo aquello que lo dotó de identidad, partió de su tierra para jamás volver. Belgrado, Nueva York, París y Normandía serían sólo los aeropuertos en el curioso vuelo de su vida. Aunque un profético rayo de luz sobre una colina durante la filmación de La Vida es Un Milagro ${ }^{7}$ lo inspiró para construir en ella Küstendorf, su propia aldea perdida entre las montañas de los Balcanes; su verdadero y único refugio lo encontraría en la estrambótica realidad de sus películas. Un lugar donde la gravedad no limita las ansias de volar, donde la muerte no es más que un pasaje a la reencarnación, donde lo onírico se hace real y desvanece el dolor para siempre. Un torrente de escenas perfectamente imperfectas, saturadas de humor negro y jarana, de detalles sobrenaturales y animales que reflejan las dolencias de su entorno mejor que cualquier ser humano. Un mundo en el que los hombres se reconocen en sus incongruencias y exudan el sufrimiento en arrebatado jolgorio. Parajes donde el alcohol, los balazos, el suicidio frustrado, el ritmo frenético de la música y el desenfreno parecen ser no sólo una vía de escape, sino también una forma de ganar renovado coraje. Historias de vida y muerte que metaforizan la usanza balcánica de oscilar sin transición entre la más excesiva brutalidad y la más patética ternura.

\section{Humor negro, tragedia y romance}

No era primera vez que partía. Su impetuosa propensión a la revuelta, que lo había hecho frecuentar pandillas de crímenes menores en los suburbios de Sarajevo, fue la razón por la que sus padres decidieron enviarlo a estudiar cine a Praga, en una "rehabilitación" que lo llevaría de vuelta a su ciudad natal para realizar sus dos primeros grandes proyectos. No obstante, ¿Recuerdas a Dolly Bell ${ }^{8}$ y Papá Salió en Viaje de Negocios se convirtieron en la causa de un nuevo y desconcertante problema. En 1982, un León de Oro en Venecia devoraba su talento de principiante y escupía una pulida mente brillante que cuatro años más tarde se adueñaría de una Palma de Oro en Cannes. A los 32 años ganaba el campeonato mundial de cine y ya no podría llegar más lejos. El shock lo hizo someterse a

\footnotetext{
${ }^{4}$ Underground (Bila Jednom Jedna Zemlja). CiBy 2000. Francia/República Federal de Yugoslavia/ Alemania/Hungría. 1995.

${ }^{5}$ Gato Negro, Gato Blanco (Crna Mačka, Beli Mačor). CiBy 2000. Francia/Alemania/República Federal de Yugoslavia. 1998.

${ }^{6}$ GIBBONS, Fiachra. I will not cult my film. Entrevista publicada en The Guardian. Gran Bretaña. 4 de marzo de 2005.

${ }^{7}$ La Vida es un Milagro (Život Je Čudo). Rasta Films. Serbia y Montenegro/Francia. 2004.

${ }^{8}$ ¿Recuerdas a Dolly Bell? (Sjecaš li se Dolly Bell?). Jadran Film/TV Sarajevo. Yugoslavia. 1981.
} 
una nueva terapia, esta vez sugerida por su amigo Nelle Karajlić, el vocalista de la subversiva banda punk Zabranjeno Pušenje: "Ya que no puedes obtener nada más con el cine, déjalo y ven a tocar con nosotros".

Seis meses de clases de bajo, un disco grabado y una gira por Yugoslavia en 1987 bastaron para que se diera cuenta del suicidio al que se estaba sometiendo. Renacería en Tiempo de Gitanos, reflejando en ella su devoción por la libertad de aquellos que yerran desembarazados del peso que entierra los pies de quienes portan una nacionalidad. Crecer, vivir y jugar con los gitanos de Sarajevo le enseñó que no es necesario un papel que materialice en un par de palabras el origen de quien lo carga, ni tampoco un país para preservar la identidad.

Nunca tuvo un sentimiento de pertenencia a su ciudad tan intenso como el que lo liaba al espíritu híbrido de su Yugoslavia que, en sólo trescientos metros cuadrados, podía reunir una iglesia ortodoxa, una iglesia católica, una sinagoga y una mezquita. Quizás porque él mismo es una amalgama de orígenes: nacido bosnio musulmán, su familia fue de aquellas serbias ortodoxas forzadas a convertirse al islam para sobrevivir los cinco siglos de dominación otomana. Asido eternamente a la concepción de un país de tantas civilizaciones, ejércitos y religiones entrelazadas, entenderá el caos no sólo como un principio intrínseco de su cultura, sino también como una forma estilística. Nacer en un lugar que no delimitaba fronteras físicas a su heterogeneidad hizo que el concepto de "límite" le fuese totalmente ajeno. No resulta curioso que su enemistad con los esquemas y las clasificaciones hagan de sus obras una mezcla de humor negro, tragedia y romance que conspira ardientemente contra las películas de género de Hollywood, la venenosa productora en serie de mercancías que aniquila el cine de autor y que él mismo intentó combatir con Sueños de Arizona ${ }^{9}$, su primera y última cinta filmada en tierras estadounidenses.

Esta visión de mundo y esta susceptibilidad balcánica serán las que, frente a una mirada occidental, conviertan a sus obras en piezas extravagantes y pintorescas; que a simple vista parecen una sobrecarga de onirismo, exhuberancia y absurdo que resulta ajena al racionalismo hegemónico de Occidente. He aquí una de las causas que explican la incomprensión, y por ende, las críticas aplastantes lanzadas desde ciertos círculos intelectuales europeos, que desconocen que para este hombre, tener el cine en sus manos significa, precisamente, cargar un arma contra un mundo dominado por la "racionalidad" occidental $^{10}$.

Si la barahúnda y la anarquía meticulosamente controladas de sus sets no se asemejan a la escena que visualiza en su mente, es capaz de enloquecer a todo su equipo hasta plasmarla en el lente de una cámara. Pero si una nueva idea se incrusta en su antojo, no duda ni un segundo en desechar la docena de noches completas que tomó acomodar en la realidad su previa intuición. Más cuando su bravo espíritu autoflagelante lo impulsa a complicar todo al extremo, peculiaridad reflejada en su afición por actores de nula experiencia y gitanos que, sin saber leer, improvisan diálogos a partir de lo que recuerdan de las grabaciones sonoras de sus walkmans.

No obstante, su tendencia a volverse loco a sí mismo y a todos los que lo rodean tiene como principal culpable un asesino deseo de que cada toma sea una original. No extraña que, así como el espectador de sus creaciones no pueda sino odiarlas o amarlas,

\footnotetext{
${ }^{9}$ Sueños de Arizona (Arizona Dream). Canal+. Estados Unidos/Francia. 1993.

${ }^{10}$ ROLLET, Sylvie. Filmer le désordre: le cinéma d'Emir Kusturica. Pág. 21. Revista Positif No417. Francia. Noviembre 1995.
} 
quienes han trabajado con él funcionen dentro de la misma dialéctica perceptiva frente a su persona. "Se le ama, se le odia. Algunos ven en él un nuevo Fellini, otros consideran que hace siempre la misma película. Jamás deja indiferente"11.

Y es que todo en él funciona con la lógica de los extremos. En sus contradicciones, en la de sus personajes, en su visión blanco y negro de la realidad, en su humor, sus cambios bruscos de ánimo y hasta en su compresión de la Historia. "Soy eslavo, nací en un límite extremadamente doloroso entre el Este y el Oeste" 12 , se excusa. Pero ni siquiera con sus mismos coterráneos podrá entenderse temperadamente, menos cuando su partida de Sarajevo a Belgrado y su rechazo a identificarse con la Bosnia brotada de las cenizas de la incinerada Yugoslavia, le echaron encima un sinfín de epítetos virulentos. No le bastaría con noquear al dirigente de la Nueva Derecha serbia, ni tampoco con retar a duelo al líder del partido Radical de la izquierda ultra-nacionalista serbia, quien prefirió rehuir de "ser acusado de la muerte de un artista" ${ }^{13}$. Sintiendo una deuda con la Historia de su país, decidió comprimir en tres horas medio siglo de tragedia balcánica para lanzar en un grito eufórico y delirante su postura frente a la guerra.

La historia de Crni y Marko, dos amigos que no solo comparten su devoción por el comunismo de Tito, sino también por la misma mujer, daría a entender que los conflictos bélicos en la ex-Yugoslavia desde la II Guerra hasta su desintegración en los 90's fue un solo proceso con distintos protagonistas. Sin embargo, Underground no hizo más que entreverar aún más el misterio sobre su (im)postura política, creando una profunda confusión de aquellas que tanto ama alistar en sus películas. Por mostrar a Tito como ídolo de sus personajes, lo acusaron de Serbio nacionalista y títere de la propaganda del entonces Presidente Slovodan Milošević, al mismo tiempo que Moscú lo catalogaba de pro-bosnio y una ola de intelectuales franceses se alzaba en su contra por "convertir en un circo" la tragedia de su tierra y lo bautizaban "criminal de guerra", "el más grande traidor de Bosnia" y "el emir de Serbia". Lo que ninguno de ellos advirtió fue que el centro de su historia era el ser humano, sus sentimientos, sinsentidos y contradicciones, y que las nacionalidades, la política y la guerra eran sólo un detalle en la escenificación. Al parecer, el jurado de Cannes había sido de los pocos en entender aquello y, mil veces más significativo que un escándalo de politiquería, le entregó la segunda Palma de Oro a su creador. Si bien muchos hablaron de su contenido y erigieron bulliciosa controversia, nadie se atrevió a atacar lo magistral de su originalidad o la brillantez estética de su puesta en escena.

\section{La lucidez del ritmo violento}

Profundamente enardecido por la polémica, volvería a tomar la decisión de dejar el cine, esta vez, según él, para siempre. Las cuatro décadas que tenía en el cuerpo le pesaban demasiado para retomar la pasión que le había dado el sentido del espacio y del trabajo en equipo aplicado en sus películas. El fútbol, para él, está lejos de ser un lote de descerebrados corriendo tras un balón, como afirman aquellos "intelectuales" que tanto le irritan. Ya imposibilitado de volver a las sinuosas y empinadas calles de su infancia o a las canchas del Bosna y del FC Sarajevo, donde jugó antes de que se convirtieran en

\footnotetext{
${ }^{11}$ DHENNIN, Matthieu. Le lexique subjectif d'Emir Kusturica. Págs. 10-11. Editorial L'Age d'Homme. Francia. Primera Edición, 2006.

${ }^{12}$ GOCIC, Goran. The Cinema of Emir Kusturica. Ediciones Wallflower Press. 2001.

${ }^{13}$ DHENNIN, Matthieu. Quelques Anecdotes. En Kustu.com:

http://www.dhennin.com/kusturica/v2/_anecdotes_fr.html (Consultado en junio de 2005).
} 
cementerios de sus propios futbolistas, se volcó una vez más a la afición que le había entregado la lucidez del ritmo violento, pero armónico de su cine.

Aunque canalizaría su explosividad y su controlado descontrol en la guitarra eléctrica de la renovada banda de su viejo amigo Nelle, la embriagadora mezcla de música gitana, folklore balcánico, punk, rock y jazz sería la causante de un nuevo y traicionero deseo de volver al cine, para narrar Gato Negro Gato Blanco, una colorida y alborozada fábula absurda sobre el pueblo de su devoción. Pero esta vez no abandonaría la rebautizada No Smoking Orchestra y partiría con ellos a esparcir por el mundo el desenfreno del Unza Unza, un ritmo tan indefinible y arrebatado como sus propios compositores. Desde entonces, los escenarios que habían sido en el pasado una terapia, se convertirían ahora en su demente, mágico y estrafalario segundo hogar.

Mientras el hiperkinético Nelle estrangula con sus manos el micrófono y no puede dejar de saltar, a su lado toca el violín un juez de barba, lentes y túnica que pasa más por psicoanalista austriaco que por el paciente con perturbaciones sexuales que parece con la peluca rubia, las zapatillas con soquetes y el escotado vestido verde que esconde bajo su vestimenta de recto hombre de ley. Tras él, un gigante con guitarra al cuello canta, rasguea y salta, cayéndosele en cada brinco un par de años del medio siglo que lleva en el cuerpo. Unos mechones más rebeldes que él mismo intentan cubrirle los ojos, hundidos por el lente de una cámara y el desgaste de la maestría. Súbitamente cae en la profundidad de su imaginación y mientras dos enamorados celebran una improvisada boda en un bote sobre el Drina, un lote de gansos persigue una limusina blanca, de la que desciende un holgazán con pinta de latin lover aspirando devotamente coca de un crucifijo. A su lado pasa corriendo una lacrimosa muchacha en dirección a una casa, donde un par de osos civilizados toma un baño en la tina y un cerdo devora una chatarra de vehículo en uno de sus costados. A falta de dos humanos, el oficial civil toma a un gato negro y uno blanco de testigos de los novios, mientras en el sótano de la morada la mujer inmersa en el mar de su llanto ata su pescuezo a una cuerda, se arroja al vacío y escucha cómo baja el agua por la cañería del w.c. al que se lió sin darse cuenta. Un gitano de walkman y lentes dorados se cruza por la cámara, el director salta, los gansos se espantan, Nelle chilla, la banda deja de tocar y enloquecido de ira le vocifera al despistado que se aprenda sus diálogos en otro lado. Fuera de sí les gruñe a todos que se vayan a sus casas, porque no usará ni un solo segundo de los doce días que llevan filmando la escena.

Cuando el rodaje llega a su fin y todo el equipo parecer querer morir del cansancio, el hombre vuelve a nacer en una vida sólo envidiable para quien quiera cometer suicidio. El día que verdaderamente deje de existir será aquel en que se agoten los sueños que inundan sus películas, en que su lucidez intelectual se extinga y ya no tenga más fuerzas para arremeter contra todo lo que huela a uniformidad, estrechez de mente, ideología y militancia. El día en que su fango de contradicciones se deshaga tal como la Yugoslavia de sus recuerdos. El día en que partirá de este y de todos sus mundos, para no volver jamás.

\section{Referencias bibliográficas y fílmicas}

DHENNIN, Matthieu. Le lexique subjectif d'Emir Kusturica. Editorial L'Age d'Homme. Francia. Primera Edición, 2006.

DHENNIN, Matthieu. Quelques Anecdotes. En Kustu.com: http://www.dhennin.com/kusturica/v2/_anecdotes_fr.html (Consultado en junio de 2005). 
GIBBONS, Fiachra. I will not cult my film. Entrevista publicada en The Guardian. Gran Bretaña. 4 de marzo de 2005.

GOCIC, Goran. The Cinema of Emir Kusturica. Ediciones Wallflower Press, 2001.

1995

GRUNBERG, Serge. Il était une fois Underground. Editorial Cahiers du Cinéma. Francia.

KUSTURICA, Emir. ¿Recuerdas a Dolly Bell? (Sjecaš li se Dolly Bell?). Jadran Film/TV Sarajevo. Yugoslavia. 1981.

KUSTURICA, Emir. Gato Negro, Gato Blanco (Crna Mačka, Beli Mačor). CiBy 2000. Francia/Alemania/República Federal de Yugoslavia. 1998.

KUSTURICA, Emir. La Vida es un Milagro (Život Je Čudo). Rasta Films. Serbia y Montenegro/Francia. 2004.

KUSTURICA, Emir. Papá Salió en Viaje de Negocios (Otac na Službenom Putu). Forum Sarajevo. Yugoslavia. 1985.

KUSTURICA, Emir. Sueños de Arizona (Arizona Dream). Canal+. Estados Unidos/Francia. 1993.

KUSTURICA, Emir. Tiempo de Gitanos (Dom za Vešanje). Forum Sarajevo. Yugoslavia/Italia/Gran Bretaña. 1989.

KUSTURICA, Emir. Underground (Bila Jednom Jedna Zemlja). CiBy 2000. Francia/República Federal de Yugoslavia/ Alemania/Hungría. 1995.

ROLLET, Sylvie. Filmer le désordre: le cinéma d'Emir Kusturica. Revista Positif No 417. Francia. Noviembre 1995 